\title{
Study of mullerian anomalies over 5 years in a tertiary care centre
}

\author{
Ramalingappa C. Antaratani, Sanjana Kumar*, Vinay Raju
}

Department of Obstetrics and Gynecology, KIMS, Hubli, Karnataka, India

Received: 20 December 2019

Revised: 20 January 2020

Accepted: 24 January 2020

\section{*Correspondence:}

Dr. Sanjana kumar,

E-mail: sanjanak60.sk@gmail.com

Copyright: (C) the author(s), publisher and licensee Medip Academy. This is an open-access article distributed under the terms of the Creative Commons Attribution Non-Commercial License, which permits unrestricted non-commercial use, distribution, and reproduction in any medium, provided the original work is properly cited.

\section{ABSTRACT}

Background: Mullerian anomalies-developmental anomalies of the mullerian system might involve the uterus, cervix, fallopian tubes and vagina of which anomalies of the uterus are the most common. They are often regarded as a treatable form of infertility and have a prevalence of $0.5 \%$ in the general population. Though most of them remain asymptomatic, they contribute a good proportion of recurrent pregnancy losses, obstetric complications and infertility. Their timely diagnosis, management and evaluation of associated anomalies proves to be necessary.

Methods: A prospective observational study was undertaken at KIMS, Hubli from 2014 to 2018. The study involved those women who were admitted in the department of obstetrics and gynecology at KIMS, Hubli for various reasons and were detected to have a mullerian anomaly. Their mode of presentation, method of detection, associated anomalies were analysed and statistical conclusions drawn from the same.

Results: During the study period of 5 years, a total of 85 cases of mullerian anomalies were detected amounting to an incidence of $0.15 \% .35 \%$ of them were asymptomatic, infertility $(24 \%)$ being the next common mode of presentation. Septate/sub-septate uterus was found to have the poorest obstetric outcome. Mullerian anomalies were seen in combination in $14 \%$ of the cases and had an association with other anomalies like renal anomalies in $10 \%$ of the cases. Surgical correction was done for most of the cases of vaginal septum and septate/sub-septate uterus.

Conclusions: Mullerian anomalies are often regarded as an uncommon but treatable form of infertility. Their timely detection, treatment and watchful obstetric management is in need.

Keywords: Hystero-laparoscopy, Infertility, Mullerian anomalies, Septate

\section{INTRODUCTION}

Congenital anomalies of the female reproductive tract may involve the uterus, cervix, fallopian tubes or vagina. Uterine anomalies are the most common mullerian anomalies but the true incidence is not known as many women are asymptomatic and sensitive imaging modalities have only recently become available. ${ }^{1,2}$ Most cases are diagnosed during evaluation for obstetric or gynaecological problems but in the absence of symptoms, most anomalies remain undiagnosed. Reported population prevalence rates have varied between $0.06 \%$ and $38 \% .^{3}$ As nearly $47 \%$ of women with uterine defects have successful fertility and pregnancy, the true incidence of congenital mullerian defects is significantly understated. Mullerian anomalies are known to be associated with renal anomalies in $30-50 \%$ of cases and defects include renal agenesis, severe renal hypoplasia, ectopic or duplicate ureters. ${ }^{3}$

\section{Clinical presentation of mullerian anomalies}

Though many women with mullerian anomalies are asymptomatic, several gynaecologic signs and symptoms are associated with specific anomalies. Women may present with cyclic or non-cyclic pelvic pain and 
dysmenorrhea suggestive of an obstructive anomaly, retrograde menstruation and endometriosis. ${ }^{1}$ Primary amenorrhea with pelvic, vaginal or back pain or a pelvic mass is concerning for a transverse vaginal septum or an imperforate hyemen. Mullerian agenesis presents with amenorrhea. Abnormal uterine bleeding may occur with a septate uterus, a partial or microperforate obstruction or a longitudinal septum. Of all mullerian anomalies, those involving the uterus are most commonly associated with poor obstetric outcomes. Uterine anomalies may be associated with diminished cavity size, inadequate musculature, impaired ability to distend, abnormal myometrial and cervical function, inadequate vascularity and abnormal endometrial development. ${ }^{2,5}$ These abnormalities of space, vascularity and associated local defects contribute to increased rates of recurrent pregnancy loss, preterm delivery, malpresentation, IUGR. ${ }^{1,6}$ An increased rate of caesarean section is associated with higher rates of malpresentation and vaginal anomalies like longitudinal vaginal septum (Figure 1).

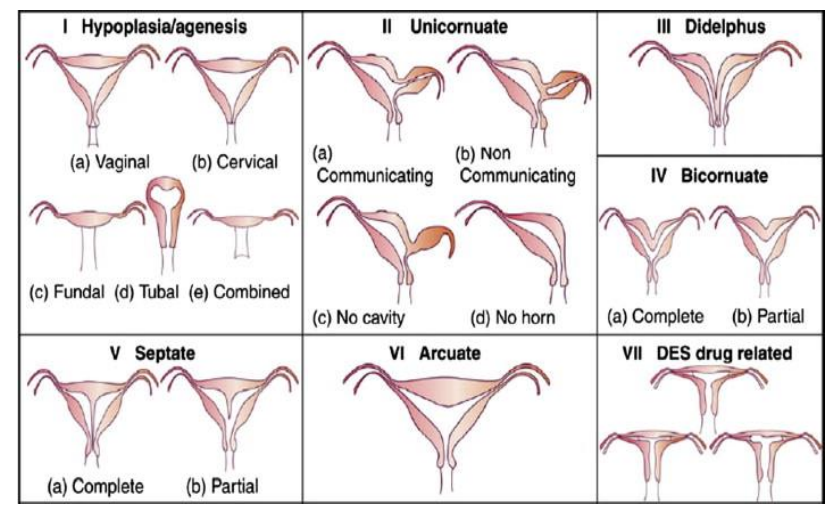

Figure 1: Classification of mullerian anomalies. ${ }^{4}$

\section{Evaluation of mullerian anomalies}

HSG is commonly used to assess patency of tubes and can provide further information about the contour of the endometrial cavity but the external uterine contour is poorly defined by $\mathrm{HSG}^{7}{ }^{7}$ Transabdominal, transvaginal or transperineal USG effectively evaluates the internal and external uterine contour. MRI is considered the gold standard technique for diagnosing mullerian anomalies and is both sensitive and specific. ${ }^{8}$ Historically, laparoscopy and hysteroscopy were the gold standard for evaluating the contour of the uterine fundus and assigning the classification to a uterine anomaly. ${ }^{9}$

\section{Surgical correction}

Surgery for mullerian anomalies is often indicated for women with pelvic pain, endometriosis, obstructive anomalies like vaginal septum, poor obstetric outcomes like RPL, infertility. Prior to performing surgery, it is important to exclude extrauterine factors which may cause pregnancy loss. ${ }^{1,2}$

\section{METHODS}

The present study was conducted among the women admitted in the department of obstetrics and gynaecology at KIMS, Hubli for various complaints with a mullerian anomaly detected during the present stay at the hospital between January 2014 to December 2018 - a period of 5 years.

\section{Inclusion criteria}

- All women admitted in the department of obstetrics and gynaecology at KIMS, Hubli with a newly detected Mullerian anomaly between January 2014 and December 2018.

\section{Exclusion criteria}

- Those with previously diagnosed Mullerian anomalies

- Women who have already undergone surgical correction of the anomaly

- Those who do not give consent to take part in the study.

Present study is a prospective observational study. Considering inclusion and exclusion criteria, selected patients were counselled regarding the study. After obtaining valid consent, a pre-designed proforma was used. Detailed clinical history regarding the presenting complaints, obstetric history, menstrual history was taken. General physical examination, systemic and necessary gynaecological examination was done. Other investigations were performed with relevance to their presenting complaints. The mode of detection of the anomaly was noted i.e., through clinical examination, imaging, hysterolaparoscopy and so on. Surgical correction feasible in our set up were done wherever necessary. However, there was no follow-up of the treated cases.

\section{Statistical analysis}

All the collected data variables were entered into an exel sheet and after appropriate data filtration, the data sheet was transferred to and analysed using SPSS software version 22. Appropriate descriptive statistics were used to describe the data.

\section{RESULTS}

The study period of 5 years between 2014 and 2018, a total of 85 cases of mullerian anomalies were detected among patients who were admitted in the department of obstetrics and gynaecology at KIMS, Hubli for various reasons. These numbers were $14,14,16,22$ and 19 in the years 2014, 2015, 2016, 2018 and 2019 respectively. The incidence was found to be $0.15 \%$ over 5 years (Table 1 ). 
Table 1: Incidence of mullerian anomalies at KIMS, Hubli.

\begin{tabular}{|lllllll|}
\hline Year $\rightarrow$ & 2014 & 2015 & 2016 & 2017 & 2018 & Total \\
\hline No of cases of mullerian anomalies detected at KIMS Hubli & 14 & 14 & 16 & 22 & 19 & 85 \\
\hline \% with respect to the total no of cases admitted & 0.13 & 0.13 & 0.15 & 0.19 & 0.18 & 0.15 \\
\hline
\end{tabular}

Table 2: Age at diagnosis of mullerian anomalies.

\begin{tabular}{|lllllllllllll|}
\hline Age at diagnosis & $\mathbf{2 0 1 4}$ & $\mathbf{\%}$ & $\mathbf{2 0 1 5}$ & $\mathbf{\%}$ & $\mathbf{2 0 1 6}$ & $\mathbf{\%}$ & $\mathbf{2 0 1 7}$ & $\mathbf{\%}$ & $\mathbf{2 0 1 8}$ & $\mathbf{\%}$ & Total & $\%$ \\
\hline$<15$ years & 1 & $\mathbf{7 . 1}$ & $\mathbf{1}$ & $\mathbf{7 . 1}$ & 0 & 0 & 1 & 4.5 & 1 & 5.2 & 4 & 4.7 \\
\hline 15-20 years & 2 & 14.2 & 1 & 7.1 & 4 & 25 & 5 & 22.7 & 2 & 10.4 & 14 & 16.4 \\
\hline $21-25$ years & 8 & 57.1 & 5 & 35.5 & 9 & 56.2 & 10 & 45.4 & 11 & 57.8 & 43 & 50.5 \\
\hline 26-30 years & 2 & 14.2 & 3 & 21.3 & 2 & 12.5 & 3 & 13.6 & 4 & 21 & 14 & 16.4 \\
\hline $31-35$ years & 0 & 0 & 2 & 14.2 & 1 & 6.2 & 0 & 0 & 0 & 0 & 3 & 3.5 \\
\hline$>35$ years & 1 & 7.1 & 2 & 14.2 & 0 & 0 & 3 & 13.6 & 1 & 5.2 & 7 & 8.2 \\
\hline
\end{tabular}

Table 3: Presentation of mullerian anomalies.

\begin{tabular}{|lllllllllllll|}
\hline Presentation & $\mathbf{2 0 1 4}$ & $\mathbf{\%}$ & $\mathbf{2 0 1 5}$ & $\mathbf{\%}$ & $\mathbf{2 0 1 6}$ & $\mathbf{\%}$ & $\mathbf{2 0 1 7}$ & $\mathbf{\%}$ & $\mathbf{2 0 1 8}$ & $\mathbf{\%}$ & Total & $\%$ \\
\hline Incidental finding & 5 & 35.7 & 2 & 14.2 & 5 & 31.2 & 9 & 40.9 & 9 & 47.3 & 30 & 35.2 \\
\hline Infertility & 1 & 7.1 & 4 & 28.5 & 7 & 43.7 & 5 & 22.7 & 3 & 15.7 & 20 & 23.5 \\
\hline Recurrent pregnancy loss & 3 & 21.3 & 2 & 14.2 & 1 & 6.2 & 1 & 4.5 & 4 & 21 & 12 & 14.1 \\
\hline Hematometra/hematocolpos & 2 & 14.2 & 1 & 7.1 & 3 & 18.7 & 1 & 4.5 & 1 & 5.2 & 8 & 9.4 \\
\hline Primary amenorrhea alone & 3 & 21.3 & 4 & 28.5 & 0 & 0 & 4 & 18.1 & 2 & 10.4 & 13 & 15.2 \\
\hline Others & 0 & 0 & 1 & 7.1 & 0 & 0 & 1 & 4.5 & 0 & 0 & 2 & 2.3 \\
\hline
\end{tabular}

The women of various age groups who were admitted at KIMS, Hubli maximum detection rate of mullerian anomalies was noted in the age group 21-25 years in all years $(50 \%)$. Very few cases were detected in women of extreme age groups (Table 2).

A large proportion (35\%) of women with mullerian anomalies were asymptomatic and the anomaly was only an incidental finding. The next common mode of presentation was infertility (24\%). This pattern was observed in the years 2014, 2017 and 2018. However, infertility was the commonest mode of presentation in 2016 constituting $44 \%$ and the commonest modes of presentation were infertility and primary amenorrhea in the year 2015 each amounting to $29 \%$. Other modes of presentation were recurrent pregnancy loss, primary amenorrhea, hematometra and hematocolpos. only 2 cases had presentations other than the above mentioned like abnormal uterine bleeding (Table 2).

Table 4: Type of mullerian anomaly.

\begin{tabular}{|lllllllllllll|}
\hline Type of anomaly & $\mathbf{2 0 1 4}$ & $\mathbf{\%}$ & $\mathbf{2 0 1 5}$ & $\mathbf{\%}$ & $\mathbf{2 0 1 6}$ & $\mathbf{\%}$ & $\mathbf{2 0 1 7}$ & $\mathbf{\%}$ & $\mathbf{2 0 1 8}$ & $\mathbf{\%}$ & Total & $\%$ \\
\hline Uterine hypoplasia/ aplasia & 3 & 21.4 & 4 & 28.5 & 0 & 0 & 2 & 9 & 2 & 10.5 & 11 & 12.9 \\
\hline Vaginal septum (horizontal) & 2 & 14.2 & 1 & 7.1 & 1 & 6.2 & 1 & 4.5 & 0 & 0 & 5 & 5.8 \\
\hline Vaginal septum (vertical) & 0 & 0 & 1 & 7.1 & 0 & 0 & 1 & 4.5 & 0 & 0 & 2 & 2.3 \\
\hline Vaginal agenesis & 0 & 0 & 0 & 0 & 1 & 6.2 & 1 & 4.5 & 0 & 0 & 2 & 2.3 \\
\hline Unicornuate uterus & 0 & 0 & 1 & 7.1 & 1 & 6.2 & 1 & 4.5 & 3 & 15.7 & 6 & 7 \\
\hline Uterus didelphys & 0 & 0 & 0 & 0 & 2 & 12.4 & 1 & 4.5 & 4 & 21 & 7 & 8.2 \\
\hline Bicornuate uterus & 4 & 28.5 & 2 & 14.2 & 5 & 31.2 & 6 & 27.2 & 4 & 21 & 21 & 24.7 \\
\hline Septate/subseptate uterus & 4 & 28.5 & 5 & 35.7 & 5 & 31.2 & 7 & 31.8 & 6 & 31.5 & 27 & 31.7 \\
\hline Arcuate uterus & 1 & 7.1 & 0 & 0 & 1 & 6.2 & 2 & 9 & 0 & 0 & 4 & 4.7 \\
\hline
\end{tabular}

An average over 5 years, the commonest mullerian anomaly was septate/sub-septate uterus (32\%). This was followed by bicornuate uterus $(25 \%)$. Considering the years separately, septate/ subseptate uterus remained the commonest anomaly in 2015, 2017 and 2018. However, septate/subseptate uterus and bicornuate uterus were detected in equal numbers in the years 2014 and 2016. (Table 4). Important tools for the detection of mullerian anomalies were clinical examination, ultrasonography, hysterosalpingography and hysterolaparoscopy. All cases 
of vaginal septum were identified by local examination and most cases of uterine aplasia/ hypoplastic uterus were picked up by USG. A large number of anomalies were detected by hysterolaparoscopy the commonest being septate/ subseptate uterus (Table 5).

Table 5: Mode of detection of various anomalies.

\begin{tabular}{|llllll|}
\hline Type of anomaly & $\begin{array}{l}\text { Detected by } \\
\text { clinical } \\
\text { examination }\end{array}$ & HSG & $\begin{array}{l}\text { Picked } \\
\text { by USG }\end{array}$ & $\begin{array}{l}\text { Diagnosed by hystero } \\
\text { laparoscopy }\end{array}$ & $\begin{array}{l}\text { Incidental finding on } \\
\text { laparotomy (most } \\
\text { commonly for LSCS) }\end{array}$ \\
\hline Hypoplastic uterus & 0 & 3 & 7 & 1 & 0 \\
\hline Unicornuate uterus & 0 & 2 & 1 & 1 & 2 \\
\hline Uterus didelphys & 1 & 2 & 1 & 2 & 1 \\
\hline Bicornuate uterus & 0 & 3 & 4 & 3 & 11 \\
\hline Septate/subseptate uterus & 0 & 4 & 0 & 16 & 7 \\
\hline Arcuate uterus & 0 & 0 & 0 & 1 & 3 \\
\hline Vaginal septum & 9 & 0 & 0 & 0 & 0 \\
\hline Total & $\mathbf{1 0}$ & $\mathbf{1 4}$ & $\mathbf{1 3}$ & $\mathbf{2 4}$ & $\mathbf{2 4}$ \\
\hline
\end{tabular}

Table 6: Surgical correction.

\begin{tabular}{|ll|}
\hline Type of anomaly & No of cases for which surgical correction was done (over $\mathbf{5}$ years) \\
\hline Hypoplastic uterus & 0 \\
\hline Unicornuate uterus & 0 \\
\hline Uterus didelphys & 0 \\
\hline Bicornuate uterus & 1 \\
\hline Septate/subseptate uterus & 16 \\
\hline Arcuate uterus & 0 \\
\hline Vaginal septum & 11 \\
\hline
\end{tabular}

Over a period of 5 years, surgical correction was done for 16 cases of septate/ sub-septate uterus (septal resection), 11 cases of vaginal septum (vaginoplasty) and 1 case of bicornuate uterus (metroplasty). Septal resection in cases of septate/sub-septate uterus diagnosed by means of hysteroscopy were done in the same sitting (Table 6).

All cases of hypoplastic uterus presented as primary amenorrhea. Unicornuate uterus was an incidental finding in most of the cases. Uterus didelphys was an incidental finding in in $43 \%$ of the cases, $43 \%$ of the cases presented with infertility (Table 7).

Bicornuate uterus was an incidental finding in $67 \%$ of the cases. The most common incidentally detected mullerian anomaly was bicornuate uterus. Patients with septate and sub-septate uterus most commonly presented as infertility (52\%). Septate/sub-septate was found to be the most common mullerian anomaly leading to infertility as well as recurrent pregnancy loss.

Table 7: Type of anomaly versus presentation.

\begin{tabular}{|c|c|c|c|c|c|c|}
\hline $\begin{array}{l}\text { Presentation } \rightarrow \\
\text { Type of anomaly }\end{array}$ & $\begin{array}{l}\text { Incidental } \\
\text { finding }\end{array}$ & Infertility & $\begin{array}{l}\text { Recurrent } \\
\text { pregnancy loss }\end{array}$ & $\begin{array}{l}\text { Primary } \\
\text { amenorrhea }\end{array}$ & $\begin{array}{l}\text { Hematometra } \\
\text { /hematocolpos }\end{array}$ & Others \\
\hline Hypoplastic uterus & 0 & 0 & 0 & 11 & 0 & 0 \\
\hline Unicornuate uterus & 5 & 0 & 1 & 0 & 0 & 0 \\
\hline Uterus didelphys & 3 & 3 & 1 & 0 & 0 & 0 \\
\hline Bicornuate uterus & 14 & 2 & 3 & 1 & 1 & 0 \\
\hline Septate /subseptate uterus & 5 & 14 & 7 & 0 & 0 & 1 \\
\hline Arcuate uterus & 3 & 1 & 0 & 0 & 0 & 0 \\
\hline Vaginal septum & 0 & 0 & 0 & 1 & 7 & 1 \\
\hline
\end{tabular}

Arcuate uterus was an incidental finding in most $(75 \%)$ of the cases.
A total $78 \%$ of the cases with vaginal septum presented with hematometra/hematocolpos and only 2 cases of 
vaginal septum had other modes of presentation like primary amenorrhea and cyclic abdominal pain.

Though mullerian anomalies were found to cause infertility and recurrent pregnancy losses in a large percentage of cases, obstetric complications were noted in only $14 \%$ of the women with mullerian anomalies the commonest complication being malpresentation. Malpresentations (most commonly breech) were noted commonly in patients with bicornuate uterus. The presence of vaginal septum led to caesarean sections in 2 cases, preterm labour was noted in 2 patients and only 1 patient presented with dystocia (septate uterus) (Table 8).

Mullerian anomalies were seen in combination in $14 \%$ of the cases. Most of them were a combination of a uterine anomaly with vaginal septum. The commonest associations were uterus didelphys with vaginal septum $(3.5 \%)$ and bicornuate uterus with vaginal septum $(3.5 \%)$ (Table 9).

Table 8: Obstetric complications.

\begin{tabular}{|lllll|}
\hline Obstetric complications $\rightarrow$ & Malpresentation & Preterm labour & Dystocia & Primary indication for LSCS \\
\hline Hypoplastic uterus & 0 & 0 & 0 & 0 \\
\hline Unicornuate uterus & 1 & 1 & 0 & 0 \\
\hline Uterus didelphys & 0 & 0 & 0 & 0 \\
\hline Bicornuate uterus & 4 & 0 & 0 & 0 \\
\hline Arcuate uterus & 1 & 0 & 0 & 0 \\
\hline Septate/subseptate uterus & 3 & 1 & 1 & 0 \\
\hline Vaginal septum & 0 & 0 & 0 & 2 \\
\hline
\end{tabular}

Table 9: Associated mullerian anomalies.

\begin{tabular}{|lll|}
\hline Associated mullerian anomalies & No. of cases & $\%$ \\
\hline Vaginal septum + uterus didelphys & 3 & 3.5 \\
\hline Vaginal septum + unicornuate uterus & 1 & 1.1 \\
\hline Vaginal septum + bicornuate uterus & 3 & 3.5 \\
\hline Vaginal septum + septate uterus & 1 & 1.1 \\
\hline Vaginal septum + arcuate uterus & 1 & 1.1 \\
\hline Bicornuate uterus with cervical stenosis & 1 & 1.1 \\
\hline Bicornuate uterus with malformed tubes & 2 & 2.3 \\
\hline Total & $\mathbf{1 2}$ & $\mathbf{1 4 . 1}$ \\
\hline
\end{tabular}

Table 10: Associated anomalies in other systems of the body.

\begin{tabular}{|lllll|}
\hline Other associations & $\begin{array}{l}\text { Absent/ ectopic } \\
\text { kidney }\end{array}$ & $\begin{array}{l}\text { Displaced or patulous } \\
\text { urethral opening }\end{array}$ & $\begin{array}{l}\text { Absent or } \\
\text { malformed ovaries }\end{array}$ & $\begin{array}{l}\text { Anal } \\
\text { stenosis }\end{array}$ \\
\hline Hypoplastic uterus & 1 & 0 & 0 & 0 \\
\hline Unicornuate uterus & 1 & 0 & 0 & 0 \\
\hline Uterus didelphys & 1 & 1 & 0 & 0 \\
\hline Bicornuate uterus & 1 & 0 & 2 & 0 \\
\hline Septate/subseptate uterus & 0 & 0 & 0 & 0 \\
\hline Arcuate uterus & 0 & 0 & & 0 \\
\hline
\end{tabular}

Nearly $10 \%$ Mullerian anomalies were found to be associated with other anomalies, the commonest being renal anomalies found in around $5 \%$ of the cases. The other anomalies that were noted were malformed ovaries, displaced urethral opening and anal stenosis (Table 10).

\section{DISCUSSION}

This study was conducted to analyze the incidence and presentations of various anomalies of the uterus as, a high degree of suspicion is required to diagnose the same and also the associated anomalies.

Among the cases admitted in the department of obstetrics and gynaecology at KIMS, Hubli between the years 2014-18 (a period of 5 years), 85 of them were diagnosed to have mullerian anomalies giving an incidence of $0.15 \%$. This is similar to the incidence of 1 in 200 to 1 in 600 i.e., 0.1 to $0.5 \%$ quoted by Rock JA et al. ${ }^{10}$ 
The commonest age group at which the mullerian anomalies were detected was 21 to 25 years in this study. the median age at diagnosis was 26 in a study conducted by Gurtcheff SE et al. ${ }^{11}$ This depends on the median age at which the women plan to conceive and seek medical help for the same in a particular population.

The mullerian anomaly was only an incidental finding in $35 \%$ of the women in this study, this being very much similar to the results of the study conducted by Gurtcheff et al, wherein the percentage of incidentally detected mullerian anomalies was $32 \% .{ }^{11}$ However, the next common mode of presentation in our study was infertility in contrast to recurrent pregnancy losses and obstetric complications in the study conducted by Gurtcheff SE et al.

About $23 \%$ of the women in whom mullerian anomalies were detected presented with infertility in comparison to the study conducted by Golan A et al wherein the incidence of unexplained infertility in women with congenital anomalies was found to be $35 \% .^{12}$

Septate / sub-septate uterus was found to have the poorest obstetrical outcome. This goes as stated by Heinonen PK et al. Associated non-mullerian congenital anomalies were found in $10 \%$ of the cases. this is similar to the study conducted by Gurtcheff SE et al, wherein this association was noted in $8.5 \%$ of the cases. Though standard authors quote an association of renal anomalies with mullerian anomalies to be $30-50 \%$, only $5 \%$ of the cases were detected to have renal anomalies in our study.

Though imaging modalities like 3D USG are the main stay of diagnosis of mullerian anomalies, diagnostic hysterolaparoscopy was a major diagnostic tool in our study especially for anomalies like septate/ sub-septate uterus and this proved beneficial as correction could be done in the same sitting. Since most of the mullerian anomalies are an incidental finding and have good obstetric outcomes, surgical correction seemed necessary only in a handful of patients majority being vaginoplasty for vaginal septum and septal resection in case of septate/sub-septate uterus.

\section{CONCLUSION}

Developmental anomalies of the mullerian system are often regarded as a treatable form of infertility. Though most of the mullerian anomalies are asymptomatic and have good obstetric outcomes, they become responsible for pregnancy losses, infertility and obstetric complications in a considerable number of cases. A high degree of suspicion is required for the timely diagnosis and treatment of mullerian anomalies and their watchful obstetric management to prevent complications. It is also necessary to keep an eye on the possible associated anomalies and syndromes.

Funding: No funding sources

Conflict of interest: None declared

Ethical approval: The study was approved by the Institutional Ethics Committee

\section{REFERENCES}

1. Lin PC, Bhatnagar KP, Nettleton GS, Nakajima ST. Female genital anomalies affecting reproduction. Fertil Steril. 2002;78:899-915.

2. Propst AM, Hill JA. Anatomic factors associated with recurrent pregnancy loss. Semin Reprod Med. 2000; 18:341-50.

3. Guimaraes Filho HA, Mattar R, Pires CR, Araujo E Jr, Moron AF, Nardozza LMM. Comparison of hysterosalpingography, hysterosonography and hysteroscopy in evaluation of the uterine cavity in patients with recurrent pregnancy losses. Arch Gynecol Obstet. 2006;274:284-8.

4. Commons C. Attribution-NonCommercialNoDerivatives 4.0 International (CC BY-NC-ND 4.0) License, 2014. Available at: https://www.researchgate.net/figure/American-fertil itysociety-classification-of-uterine-malformations4_fig4_261916647. Accessed on 23 ${ }^{\text {rd }}$ February 2019.

5. Simon C, Martinez L, Pardo F, Tortajada M, Pellicer A. $\mathrm{Mu}$ "llerian defects in women with normal reproductive outcome. Fertil Steril. 1991;56:1192-3.

6. Fedele L, Bianchi S. Hysteroscopic metroplasty for septate uterus. Obstet Gynecol Clin North Am. 1995;22:4.

7. Troiano RN, McCarthy SM. Mu "llerian duct anomalies: imaging and clinical issues. Radiol. 2004;233:19-34.

8. Pellerito JS, McCarthy SM, Doyle MB, Glickman MG, DeCherney AH. Diagnosis of uterine anomalies: relative accuracy of MR imaging, endovaginal sonography, and hysterosalpingography. Radiol. 1992;183:795-800.

9. Homer HA, Li TC, Cooke ID. The septateuterus: are view of management and reproductive outcome. Fertil Steril. 2000;73:1-14.

10. Rock JA, Schlaff WD. The obstetric consequences of utero vaginal anomalies. Fertil Steril. 1985;43:681.

11. Golan A, Langer R, Bukovsky I, Caspi E. Congenital anomalies special clinical situations or suspected malformation. Currently, of the mu“ llerian system. Fertil Steril. 1989;51:747-55.

12. Gurtcheff SE, Hatasaka H, Lamber P, Empey R, Morris E, Hammoud A. Clinical presentation of Mullerian anomalies in a large population cohort. Fertil Steril. 2008;90(1):S153-4.

Cite this article as: Antaratani RC, Kumar S, Raju V. Study of mullerian anomalies over 5 years in a tertiary care centre. Int J Reprod Contracept Obstet Gynecol 2020;9:1083-8. 